\title{
Dietary fat and bile juice, but not obesity, are responsible for the increase in small intestinal permeability induced through the suppression of tight junction protein expression in LETO and OLETF rats
}

Takuya Suzuki ${ }^{1,2}$, Hiroshi Hara ${ }^{1 *}$

\begin{abstract}
Background: An increase in the intestinal permeability is considered to be associated with the inflammatory tone and development in the obesity and diabetes, however, the pathogenesis of the increase in the intestinal permeability is poorly understood. The present study was performed to determine the influence of obesity itself as well as dietary fat on the increase in intestinal permeability.

Methods: An obese rat strain, Otsuka Long Evans Tokushima Fatty (OLETF), and the lean counter strain, Long Evans Tokushima Otsuka (LETO), were fed standard or high fat diets for 16 weeks. Glucose tolerance, intestinal permeability, intestinal tight junction (TJ) proteins expression, plasma bile acids concentration were evaluated. In addition, the effects of rat bile juice and dietary fat, possible mediators of the increase in the intestinal permeability in the obesity, on TJ permeability were explored in human intestinal Caco-2 cells.

Results: The OLETF rats showed higher glucose intolerance than did the LETO rats, which became more marked with the prolonged feeding of the high fat diet. Intestinal permeability in the OLETF rats evaluated by the urinary excretion of intestinal permeability markers (Cr-EDTA and phenolsulfonphthalein) was comparable to that in the LETO rats. Feeding the high fat diet increased intestinal permeability in both the OLETF and LETO rats, and the increases correlated with decreases in TJ proteins (claudin-1, claudin-3, occludin and junctional adhesion molecule1) expression in the small, but not in the large intestine (cecum or colon). The plasma bile acids concentration was higher in rats fed the high fat diet. Exposure to bile juice and the fat emulsion increased TJ permeability with concomitant reductions in TJ protein expression (claudin-1, claudin-3, and junctional adhesion molecule-1) in the Caco-2 cell monolayers.
\end{abstract}

Conclusion: Excessive dietary fat and/or increased levels of luminal bile juice, but not genetic obesity, are responsible for the increase in small intestinal permeability resulting from the suppression of TJ protein expression.

\section{Background}

Obesity is associated with a cluster of metabolic disorders such as diabetes, hyperlipidemia, and cardiovascular diseases. The high prevalence of obesity and type 2 diabetes is becoming a serious socioeconomic and clinical problem in developed countries [1]. It has been reported

\footnotetext{
* Correspondence: hara@chem.agr.hokudai.ac.jp
'Division of Applied Bioscience, Research Faculty of Agriculture, Hokkaido

* Correspondence: hara@chem.agr.hokudai.ac.jp
'Division of Applied Bioscience, Research Faculty of Agriculture, Hokkaido University, Sapporo, Hokkaido, Japan
}

C) RHed Central

(c) 2010 Suzuki and Hara; licensee BioMed Central Ltd. This is an Open Access article distributed under the terms of the Creative Commons Attribution License (http://creativecommons.org/licenses/by/2.0), which permits unrestricted use, distribution, and reproduction in any medium, provided the original work is properly cited.
States can be classified as obese. Understanding the origin and features of obesity and diabetes is crucial for limiting prevalence. It is known that obesity and diabetes are the results of a complex interaction between genetic and environmental factors. Among the environmental factors, preference for a fat-enriched diet, excessive calorie intake, and a sedentary life style increase the occurrence and promote the progression of metabolic disorders. 
Recently, obesity and diabetes have been characterized by low-grade chronic systemic inflammation [2], and an innovative hypothesis was proposed: this systemic inflammation is closely linked to the plasma endotoxemia resulting from increased intestinal permeability in obese animals $[3,4]$. Cani et al. [4] demonstrated that feeding a high fat diet increased intestinal permeability in mice, which was normalized by simultaneous antibiotic treatment. They suggested that the high fat-induced changes in the gut microflora increased intestinal permeability. Meanwhile, Brun et al. [5] reported that genetic obesity models, leptin-deficient (ob/ob) and leptin receptor-deficient $(\mathrm{db} / \mathrm{db})$ mice, displayed similar increases in intestinal permeability although these mice were fed a standard chow. Thus, the pathogenesis of the increase in intestinal permeability in obesity remains controversial.

A major determinant of intestinal permeability is the intercellular tight junctions (TJs), which are positioned around the apical end of the lateral cell membrane of intestinal epithelial cells [6]. TJs are organized by specific interactions between a wide spectrum of proteins, and three integral transmembrane proteins, occludin [7], claudin [8], and junctional adhesion molecule (JAM) [9], have been identified. These interact with other intracellular plaque proteins such as Zonula Occludens (ZO)-1, $\mathrm{ZO}-2$, ZO-3, cingulin, and 7H6, which in turn anchor the transmembrane proteins to the actin cytoskeleton [6]. It is known that the association of $\mathrm{TJ}$ proteins with the perijunctional actin cytoskeleton ring is vital for the maintenance of TJ structure and function [10]. Stimuli, such as nutrients and cytokines, have been reported to influence not only the expression of $\mathrm{TJ}$ proteins but also their association with the actin cytoskeleton [11].

The aim of the present study is to explore the pathogenesis of the increase in intestinal permeability in obesity and diabetes. The effect of high-fat feeding on intestinal permeability and TJ protein expression/cytoskeletal association was investigated in another obesity model, OLETF (Otsuka Long-Evans Tokushima Fatty) rats, and the lean counter strain, LETO (Long-Evans Tokushima Otsuka) rats. In addition, based on the results from the animal study, the influences of fat and bile juice on the high-fat feeding-induced increase in TJ permeability were examined using human intestinal Caco-2 cells.

\section{Methods}

\section{Chemicals}

Rabbit anti-claudin-1, claudin-3, and JAM-1 and horseradish peroxidase (HRP)-conjugated mouse anti-occludin were purchased from Zymed Laboratories (San Francisco, CA). Mouse anti- $\beta$-actin and HRP-conjugated anti-mouse and -rabbit IgG were purchased from Sigma
(St. Louis, MO). Cell culture reagents and supplies were purchased from Invitrogen (Carlsbad, CA). All other chemicals were obtained from Wako Pure Chemical Industries (Osaka, Japan).

\section{Animals and diets}

Male Otsuka Long-Evans Tokushima Fatty (OLETF; $\mathrm{n}=$ 18) rats and the lean counter strain, Long-Evans Tokushima Otsuka (LETO; $\mathrm{n}=18$ ) rats, were kindly provided by Otsuka Pharmaceutical Co., Ltd. (Tokushima, Japan; 4 weeks old). Rats were housed in individual cages in a room with controlled temperature $\left(23 \pm 1^{\circ} \mathrm{C}\right)$, relative humidity $(55 \pm 5 \%$ ), and lighting (lights on from 8:00 to 20:00) throughout the study. Body weight and food intake were measured every 2 nd day. The rats had free access to tap water and a standard diet (AIN93G formula, Table 1) for an acclimation period of 1 week. The OLETF and LETO rats were each divided into 2 groups, the standard and high fat diet groups, on the basis of body weight (Table 1). The high fat diet contained $7 \%$ soybean oil and $23 \%$ lard by weight. Rats had free access to each experimental diet for 16 weeks. At the end of the experiment, blood was drawn from the abdominal aorta under anesthesia (Nembutal: sodium pentobarbital, $40 \mathrm{mg} / \mathrm{kg}$ body weight; Abbott Japan Co., Ltd., Tokyo, Japan) for the measurement of tumor necrosis factor (TNF)- $\alpha$, interferon (IFN)- $\gamma$, leptin, and total bile acids, and rats were then killed by exsanguination. The mucosa of the small intestine, cecum, and colon were scraped using a glass slide and subjected to preparations of whole cell extract and the detergent-insoluble fraction as described below. The

\section{Table 1 Composition of test diets}

\begin{tabular}{|c|c|c|}
\hline \multirow[t]{2}{*}{ Ingredient } & Standard diet & High fat diet \\
\hline & \multicolumn{2}{|c|}{$\mathrm{g} / \mathrm{kg}$ diet } \\
\hline Casein $^{1}$ & 200 & 200 \\
\hline Corn starch ${ }^{2}$ & 429.5 & 199.5 \\
\hline Dextrin $^{3}$ & 100 & 100 \\
\hline Sucrose ${ }^{4}$ & 100 & 100 \\
\hline Soy bean oil & 70 & 70 \\
\hline Lard & 0 & 230 \\
\hline Choline bitartrate & 2.5 & 2.5 \\
\hline L-cystine & 3 & 3 \\
\hline Mineral mixture ${ }^{5}$ & 35 & 35 \\
\hline Vitamin mixture ${ }^{5}$ & 10 & 10 \\
\hline Cellulose $^{6}$ & 50 & 50 \\
\hline
\end{tabular}

${ }^{1}$ Casein (ALACID; New Zealand Daily Board, Wellington, New Zealand).

${ }^{2}$ Corn Starch ( $\alpha$-Corn Starch; Chuou Shokuryo Co., Ltd., Inazawa, Japan).

${ }^{3}$ Dextrin (TK-16; Matsutani Chemical Industry Co., Ltd. Itami, Japan).

${ }^{4}$ Sucrose (Nippon Beet Sugar Manufacturing Co., Ltd., Tokyo, Japan).

${ }^{5}$ Mineral and vitamin mixtures were prepared according to the AIN-93G formulation.

${ }^{6}$ Crystallized cellulose (Ceolus PH102; Asahi Chemical Industry, Tokyo, Japan). 
liver and fat pads (mesenteric, epididymal and retroperitoneal) were removed and weighed. The mesenteric fat pad consisted of adipose tissue surrounding the gastrointestinal tract from the gastro-oesophageal sphincter to the end of the rectum. The retroperitoneal fat pad was taken as the distinct deposit on the back of abdominal wall including that around each kidney. This study was approved by the Hokkaido University Animal Committee, and the rats were maintained in accordance with the Hokkaido University guidelines for the care and use of laboratory animals (Approval number: 08-0137).

\section{Oral glucose tolerance test (OGTT)}

Oral glucose tolerance tests were performed 2, 8 and 15 weeks after the onset of feeding as described previously [12]. Briefly, the rats were fasted for $8 \mathrm{~h}$ before the administration of an oral glucose load ( $2 \mathrm{~g} / \mathrm{kg}$ body weight; $200 \mathrm{~g} / \mathrm{L}$ solution). Blood samples were collected from the tail vein at 0 (before administration), 15, 30, 60, and 120 min after administration of the glucose load. Blood samples were immediately centrifuged $(1300 \times \mathrm{g}$ for $15 \mathrm{~min}$ at $4^{\circ} \mathrm{C}$ ) and the plasma was separated. Plasma glucose concentration was assayed by an enzymatic method using a commercially available kit (Glucose CII Test Wako, Wako Pure Chemical Industries). The area under the glucose curve (AUC) was then calculated. Plasma insulin concentration on 15 weeks was assayed by ELISA (Rat Insulin ELISA KIT, Shibayagi, Gunma, Japan). Homeostasis model assessment insulin resistance (HOMA-IR) was calculated as an indicator of insulin resistance on 15 weeks according to the formula: HOMA-IR $=$ Fasting glucose $(\mathrm{mM}) \times$ Fasting insulin $(\mu \mathrm{U} / \mathrm{mL}) / 22.5$. Plasma triglyceride concentration at $0 \mathrm{~min}$ was also measured using a commercially available kit (TG-EN Kainos, Kainos Laboratories, Tokyo, Japan).

\section{Plasma total bile acid, TNF- $\alpha$, IFN- $\boldsymbol{\gamma}$, and leptin concentrations}

The plasma was separated from the blood collected from the abdominal aorta at the end of the experiment. The total bile acid concentration in the plasma was assayed by an enzymatic method using a commercially available kit (TBA Test Wako, Wako Pure Chemical Industries). TNF- $\alpha$, IFN- $\gamma$, and leptin concentrations were assayed by ELISA (Rat TNF- $\alpha$ US ELISA kit, Invitrogen; Rat IFN $\gamma$ ELISA kit, Pierce Biotechnology, Rockford, IL; Rat leptin ELISA kit, LINCO Research, St. Charles, MO).

\section{Intestinal permeability test}

Intestinal permeability was evaluated using phenolsulfonphthalein (PSP) [13] and Cr-EDTA [14]. These markers pass through the paracellular routes, but not transcellular routes, of the intestinal epithelial cells into the blood stream and are excreted in the urine without being metabolized in the body. Phenolsulfonphthalein [5 $\mathrm{mg} / \mathrm{kg}$ body weight, $1 \%(\mathrm{w} / \mathrm{v})$ PSP solution] at 3 weeks and Cr-EDTA (450 $\mu \mathrm{mol} \mathrm{Cr}$-EDTA/kg body weight, 90 mmol Cr-EDTA/L solution) at 9 and 15 weeks were intragastrically administrated to the rats. Cr-EDTA was prepared as described previously [15]. The total urine was collected for $48 \mathrm{~h}$ after administration of the PSP and Cr-EDTA loads and diluted to $100 \mathrm{~mL}$ with deionized water. The PSP concentration was colorimetrically determined at a wavelength of $560 \mathrm{~nm}$ after the addition of sodium hydroxide (final concentration, $0.4 \mathrm{M}$ ) to the diluted urine. For the measurement of Cr-EDTA, ammonium chloride (final concentration, $0.2 \mathrm{~g} / \mathrm{L}$ ) and perchloric acid (final concentration, $3.5 \%$ ) were added to the diluted urine and $\mathrm{Cr}$ concentrations in the supernatant obtained upon centrifugation $(5,000 \times \mathrm{g}$ for $15 \mathrm{~min}$ at $4^{\circ} \mathrm{C}$ ) were measured by atomic absorption spectrophotometry (AA-6400F; Shimadzu Corporation, Kyoto, Japan). The urinary PSP and Cr-EDTA excretions ratios were expressed as a percentage of the amounts administered.

\section{Immunofluorescence}

Segments of the small intestine, cecum, and colon were embedded in OCT compound (Sakura Finetek Japan Co. Ltd., Tokyo, Japan) after fixation with $4 \%$ paraformaldehyde in PBS. Frozen sections ( $7 \mu \mathrm{m}$ in thickness) were prepared on glass slides and washed with PBS. The sections were blocked in $10 \%$ normal goat serum and incubated for $16 \mathrm{~h}$ at $4^{\circ} \mathrm{C}$ with rabbit polyclonal anticlaudin-3, followed by incubation for $1 \mathrm{~h}$ with goat AlexaFluor 488-conjugated anti-rabbit IgG and rhodamine-conjugated phalloidine. The sections were preserved in a mounting medium containing DAPI (ProLong ${ }^{\oplus}$ Gold Antifade Reagent, Invitrogen), and the fluorescence was visualized using a Leica FW4000 fluorescence microscope (Leica Microsystems, Germany).

\section{Experiments in intestinal epithelial Caco-2 cells}

To explore the effects of rat bile juice and fat on intestinal TJ integrity, human intestinal Caco- 2 cells were used (HTB-37; American Type Culture Collection, Rockville, MD). The Caco-2 cells were propagated and maintained under standard cell culture conditions as described previously [11]. The cells were seeded into permeable polyester membrane filter supports (Transwell, $12 \mathrm{~mm}$ diameter, $0.4 \mu \mathrm{m}$ pore size; Corning Costar Co., Cambridge, MA) at a density of $0.25 \times 10^{6}$ cells/ $\mathrm{cm}^{2}$. Cultures were used between passage 40 and 50 , and the medium was refreshed every 3 days.

Rat bile juice was collected from 3 male Wistar/ST rats (7 weeks old; SLC Japan, Shizuoka, Japan) fed the high fat diet for at least one week. Briefly, a silicon 
cannula (Silascon SH No.00; Kaneka Medix, Osaka, Japan) was implanted in the rat bile duct and the bile juice was spontaneously collected for $3 \mathrm{~h}$ under anesthesia (sodium pentobarbital, $40 \mathrm{mg} / \mathrm{kg}$ body weight). The total bile acid concentration in the rat bile juice collected was quantified using the commercially available kit described above. An intravenous fat emulsion (10\% Intralipid ${ }^{\circledR}$; TERUMO, Tokyo, Japan) was used as the fat source and contained $10 \%(\mathrm{w} / \mathrm{v})$ soybean oil, $1.2 \%$ $(\mathrm{w} / \mathrm{v})$ lecithin, and $2.25 \%(\mathrm{w} / \mathrm{v})$ glycerol.

Intestinal $\mathrm{TJ}$ integrity was evaluated by measurement of transepithelial electrical resistance (TER) and unidirectional flux of lucifer yellow (LY) in Caco-2 cell monolayers in Transwell filter supports [11]. The rat bile juice $[0,1.02 .5,5.010$, and $20 \%(\mathrm{v} / \mathrm{v})]$ and fat emulsion $[0$, $0.1,0.25,0.5$, and $1 \%$ fat $(\mathrm{w} / \mathrm{v})]$ were administrated to the apical wells on day 12 and the cells were maintained for $72 \mathrm{~h}$. The effect of the combination of the bile juice (10\%) and fat emulsion $(0.5 \%)$ on the $\mathrm{TJ}$ permeability was also examined. The lecithin and glycerol concentrations were adjusted to $0.12 \%$ and $0.225 \%$ in the apical solutions of all treatments in the series of experiments using the fat emulsion. The medium was refreshed every day. TER was measured every $24 \mathrm{~h}$ after administration of the test agents using a Millicell-ERS system (Millipore, Bedford, MA). Lucifer yellow (LY; $100 \mu \mathrm{mol} / \mathrm{L})$, a paracellular marker, was injected into the apical wells at $69 \mathrm{~h}$ post administration of the bile juice and fat emulsion, and the flux into the basal wells was assessed for $3 \mathrm{~h}$. The concentration of LY in the basal solution was determined by fluorescence measurement (FP-550; JASCO International Co., Ltd., Tokyo, Japan). Whole extract of cells incubated with the bile juice $(0,10$, and $20 \%)$ and fat emulsion (0, 0.5, and $1 \%$ ) for $72 \mathrm{~h}$ was prepared for immunoblot analysis of $\mathrm{TJ}$ proteins as described below.

\section{Preparation of whole cell extract and the detergent- insoluble fraction}

Whole cell extract and the detergent-insoluble fraction of the rat intestinal mucosa and Caco-2 cells were prepared as described previously $[11,16]$, with the latter corresponding to the TJ proteins associated with the actin cytoskeleton. For preparation of the whole cell extract, $50 \mathrm{mg}$ of rat mucosa (small intestine, cecum, and colon) was lysed with $500 \mu \mathrm{L}$ of RIPA buffer ( $1 \%$ Nonidet P-40, 0.5\% sodium deoxycholate, 0.1\% SDS, 150 $\mathrm{mmol} / \mathrm{L} \mathrm{NaCl}, 1 \mathrm{mmol} / \mathrm{L}$ EGTA, and $1 \mathrm{mmol} / \mathrm{L}$ EDTA in $25 \mathrm{mmol} / \mathrm{L}$ Tris containing protease inhibitors and phosphatase inhibitors, $\mathrm{pH}$ 7.5). Two hundred $\mu \mathrm{L}$ of RIPA buffer was added to the Caco- 2 cells in each well after washing the cell monolayers with ice-cold PBS. To prepare the detergent-insoluble fraction, $50 \mathrm{mg}$ of rat mucosa was suspended with $500 \mu \mathrm{L}$ of lysis buffer-CS
(1\% TritonX-100, $5 \mathrm{mmol} / \mathrm{L}$ EGTA in $50 \mathrm{mmol} / \mathrm{L}$ Tris containing protease and phosphatase inhibitors, $\mathrm{pH} 7.5$ ) and incubated for $15 \mathrm{~min}$ at $4^{\circ} \mathrm{C}$. Cell lysates were centrifuged at $15,600 \times \mathrm{g}$ for $5 \mathrm{~min}$ at $4^{\circ} \mathrm{C}$ to sediment the high density actin-rich fraction. The pellet corresponding to the detergent-insoluble fraction was suspended in $300 \mu \mathrm{L}$ of RIPA buffer. Protein concentrations in the lysates were measured using the BCA method (Pierce Biotechnology, Inc., Rockford, IL). The lysates were mixed with a half volume of $3 \times$ concentrated Laemmli sample buffer [17] and heated at $100^{\circ} \mathrm{C}$ for $5 \mathrm{~min}$.

\section{Immunoblot analysis}

Proteins $(50 \mu \mathrm{g}$ of the rat mucosa and $20 \mu \mathrm{g}$ of the Caco- 2 cells) were separated by SDS-PAGE (12\%) and transferred to polyvinylidene difluoride membranes. Membranes were blotted for occludin, claudin-1, claudin-3, JAM-1, and $\beta$-actin using specific antibodies in combination with HRP-conjugated anti-mouse IgG or anti-rabbit IgG antibodies. The blots were developed using the ECL chemiluminescence method (GE Healthcare, Buckinghamshire, UK). Quantification was performed by densitometric analysis of specific bands on the immunoblots using Image J software.

\section{Statistical analysis}

All values are expressed as means \pm SEM. Statistical analyses were performed by 1 - or 2-way ANOVA (analysis of variance) or repeated measure 1- or 2-way ANOVA followed by Duncan's multiple range test. A difference with $P<0.05$ was considered significant. Statistical analyses were performed using the general linear models procedure of the SAS program (version 6.07; SAS Institute).

\section{Results}

\section{Body weight, food intake, and tissues weights}

Body weights at 0 (initial), 2, 8, and 16 (final) weeks, food intake, and energy intake were all influenced by strain, and all parameters except for the initial body weight were influenced by the diet as well $(P<0.05$, 2 -way ANOVA, Table 2). The final body weight and energy intake were higher in the OLETF than in the LETO rats and were higher in the high fat diet groups than in the standard diet groups in each strain.

Liver and total fat pad (mesenteric, epididymal, and retroperitoneal fat pads) weights were strongly influenced by both strain and $\operatorname{diet}(P<0.05,2$-way ANOVA, Table 2). These 2 parameters in the OLETF rats were much higher than in the LETO rats with the total fat pad weights in the LETO rats fed the high fat diet and in the OLETF rats fed the standard and high fat diets being 1.9-, 3.0-, and 4.6-fold higher, respectively, than that in the LETO rats fed the standard diet,. 
Table 2 Initial body weight, final body weight, food intake, energy intake, liver weight, and fat pad weight

\begin{tabular}{|c|c|c|c|c|c|c|c|c|c|}
\hline \multirow[b]{3}{*}{ Strain } & \multirow[b]{3}{*}{ Diet } & \multicolumn{4}{|c|}{ Body weights } & \multirow{3}{*}{$\begin{array}{c}\text { Food intake } \\
\text { g/day }\end{array}$} & \multirow{3}{*}{$\begin{array}{c}\text { Energy intake } \\
\text { cal/day }\end{array}$} & \multirow{3}{*}{$\begin{array}{c}\text { Liver weight } \\
\text { g/rat }\end{array}$} & \multirow{3}{*}{$\begin{array}{c}\text { Fat pad weight } \\
\text { g/rat }\end{array}$} \\
\hline & & 0 week & 2 weeks & 8 weeks & 16 weeks & & & & \\
\hline & & g & g & g & g & & & & \\
\hline \multirow[t]{2}{*}{ LETO } & Standard & $91.5 \pm 1.9 b$ & $189 \pm 14 b$ & $365 \pm 10 d$ & $461 \pm 13 d$ & $18.2 \pm 0.4 \mathrm{C}$ & $71.9 \pm 1.7 \mathrm{~d}$ & $9.49 \pm 0.28 c$ & $25.0 \pm 2.4 \mathrm{~d}$ \\
\hline & High fat & $89.4 \pm 1.3 b$ & $195 \pm 2 b$ & $420 \pm 6 c$ & $551 \pm 28 c$ & $15.8 \pm 0.2 \mathrm{~d}$ & $80.5 \pm 1.2 c$ & $9.74 \pm 0.34 c$ & $47.2 \pm 3.1 c$ \\
\hline \multirow[t]{2}{*}{ OLETF } & Standard & $114 \pm 1.9 \mathrm{a}$ & $242 \pm 3 a$ & $500 \pm 6 b$ & $655 \pm 35 b$ & $25.1 \pm 0.5 \mathrm{a}$ & $99.5 \pm 1.7 b$ & $17.2 \pm 0.67 b$ & $76.1 \pm 2.3 b$ \\
\hline & High fat & $114 \pm 1.5 \mathrm{a}$ & $258 \pm 7$ a & $606 \pm 16 a$ & $769 \pm 49 a$ & $22.8 \pm 0.4 b$ & $116 \pm 2.5 \mathrm{a}$ & $22.6 \pm 0.81 \mathrm{a}$ & $114 \pm 4.3 \mathrm{a}$ \\
\hline \multirow[t]{3}{*}{ 2-way ANOVA } & Strain & $<0.01$ & $<0.01$ & $<0.01$ & $<0.01$ & $<0.01$ & $<0.01$ & $<0.01$ & $<0.01$ \\
\hline & Diet & 0.52 & 0.03 & $<0.01$ & 0.06 & $<0.01$ & $<0.01$ & $<0.01$ & $<0.01$ \\
\hline & $S \times D$ & 0.54 & 0.43 & 0.12 & $<0.01$ & 0.93 & 0.04 & $<0.01$ & 0.92 \\
\hline
\end{tabular}

Each value represents mean $\pm \mathrm{SEM}, \mathrm{n}=9$. Means without a common letter differ, $\mathrm{P}<0.05$.

${ }^{1}$ Fat pad weight: sum of mesenteric, epididymal and retroperitoneal fat pads weights

\section{Oral glucose tolerance test (OGTT)}

The OLETF rats showed higher glucose intolerance than did the LETO rats, which became more marked with the prolonged feeding of the high fat diet (Fig. 1). At 2 (Fig. 1A), 8 (Fig. 1C), and 15 (Fig. 1E) weeks, the plasma glucose concentrations in the OLETF rats fed the standard and high fat diets were higher than those in the LETO rats fed the same diets at 15, 30, and 60 min post glucose challenge. Within the OLETF rats, the glucose concentrations in the high fat diet group were higher than those in the standard diet group at 30, 60, and $120 \mathrm{~min}$ in all tests. The area under the glucose curve (AUC) was influenced by both strain and diet at 2 (Fig. 1B), 8 (Fig. 1D) and 15 (Fig. 1F) weeks $(P<0.05,2$-way ANOVA), and the AUC values in the OLETF rats were higher than those in the LETO rats in all tests. In the OLETF rats, the AUC in the high fat diet group was higher than that in the standard diet group in all tests. The plasma insulin concentrations in the OLETF rats fed the standard and high fat diets for 15 weeks were higher than those in the LETO rats fed the standard diet at all time points (Fig. 1G). Within the LETO rats, the insulin concentrations in the high fat diet group were higher than those in the standard diet group at 30, 60 , and $120 \mathrm{~min}$. The HOMA-IR was influenced by both strain and diet on 15 weeks (Fig. $1 \mathrm{H} ; \mathrm{P}<0.05$, 2 -way ANOVA), and the HOMA-IR in the OLETF rats were higher than those in the LETO rats.

\section{Concentrations of blood glucose, triglyceride, TNF- $\alpha$, IFN-} $\gamma$, leptin, and bile acid

The plasma glucose and triglyceride concentrations under fasting conditions before and at 2, 8, and 15 weeks after feeding were assayed (Fig. 2A and 2B). Before the start of feeding (on 0 week), the plasma glucose concentration in the OLETF rats was higher than that in the LETO rats. At 2, 8, and 15 weeks, the glucose concentrations in the OLETF rats fed the standard and high fat diets were higher than that in the LETO rats fed the standard diet, and the glucose level in the OLETF rats fed the high fat diet was much higher than those in the other groups at 15 weeks. At 2, 8, and 15 weeks, the plasma triglyceride concentrations in the OLETF rats were much higher than those in the LETO rats. In the OLETF rats, the triglyceride concentration in the high fat diet group was lower than that in the standard diet group at 15 weeks.

The plasma TNF- $\alpha$ (Fig. 2C), IFN- $\gamma$ (Fig. 2D), and leptin (Fig. 2E) concentrations at 15 weeks were higher in the OLETF rats than in the LETO rats $(P<0.05,2$-way ANOVA). The TNF- $\alpha$ concentration in the OLETF rats fed the high fat diet was much higher compared with those in the other groups. The IFN- $\gamma$ concentrations in the OLETF rats were much higher than those in the LETO rats. The leptin concentrations were markedly higher in the OLETF rats than in the LETO rats, and feeding the high fat diet increased the leptin levels in rats of both strains (Fig. 2E). The total bile acid concentration in the plasma was increased by feeding the high fat diet in both strains, but the high fat-induced increase was much larger in the OLETF rats (Fig. 2F). There was no difference in bile acid level between the OLETF and LETO rats in the standard diet group.

\section{Intestinal permeability test}

The urinary excretion of PSP and Cr-EDTA, intestinal permeability markers, was measured for $48 \mathrm{~h}$ after oral administrations (Fig. 3). The urinary PSP at 3 weeks (Fig. 3A) and Cr-EDTA at 9 (Fig. 3B) and 15 (Fig. 3C) weeks were influenced by $\operatorname{diet}(P<0.05,2$-way ANOVA), and excretion levels in the high fat diet groups were higher than those in the standard diet groups in all tests. Excretion levels tended to be lower in the OLETF rats than in the LETO rats within the 


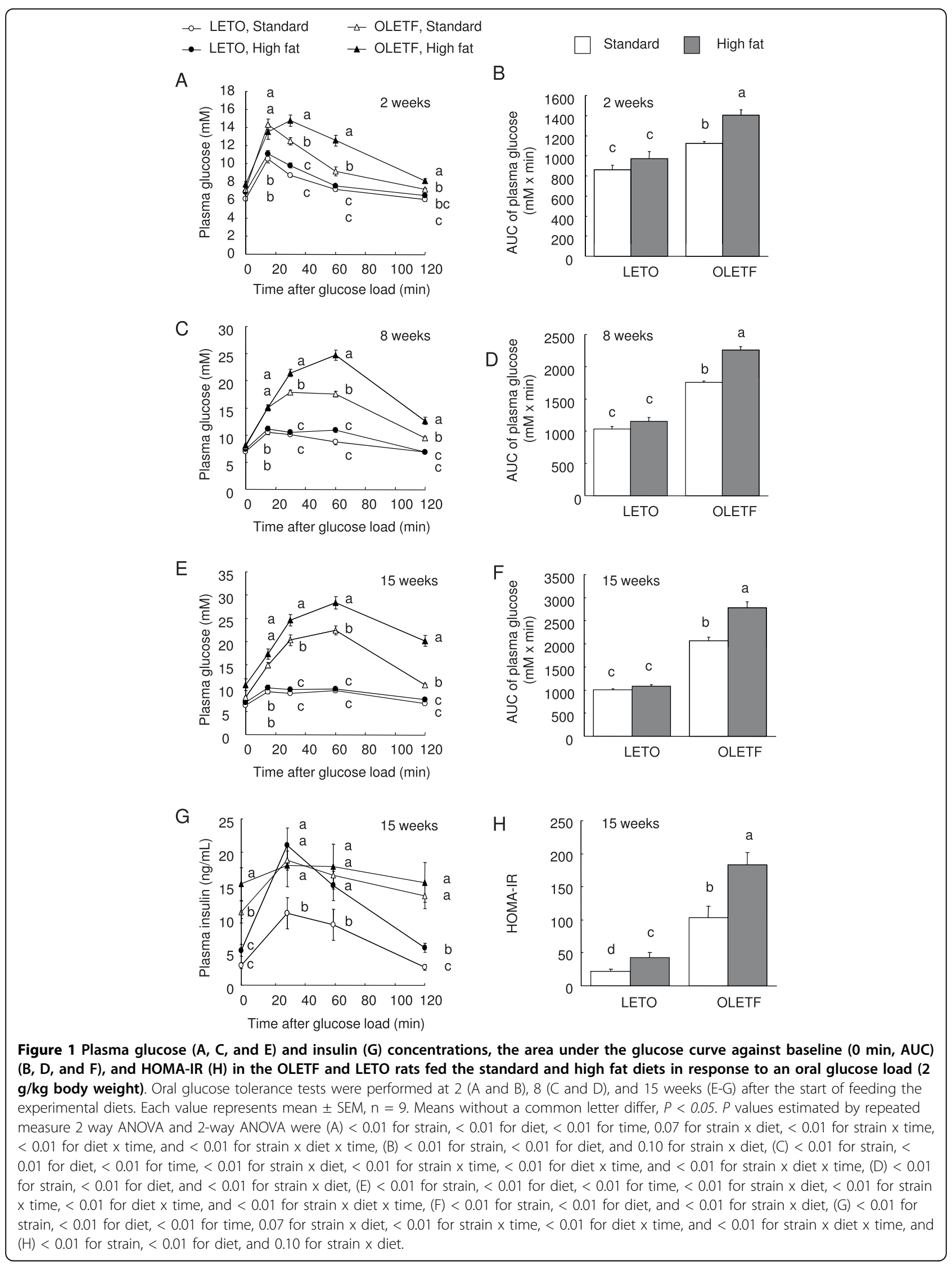



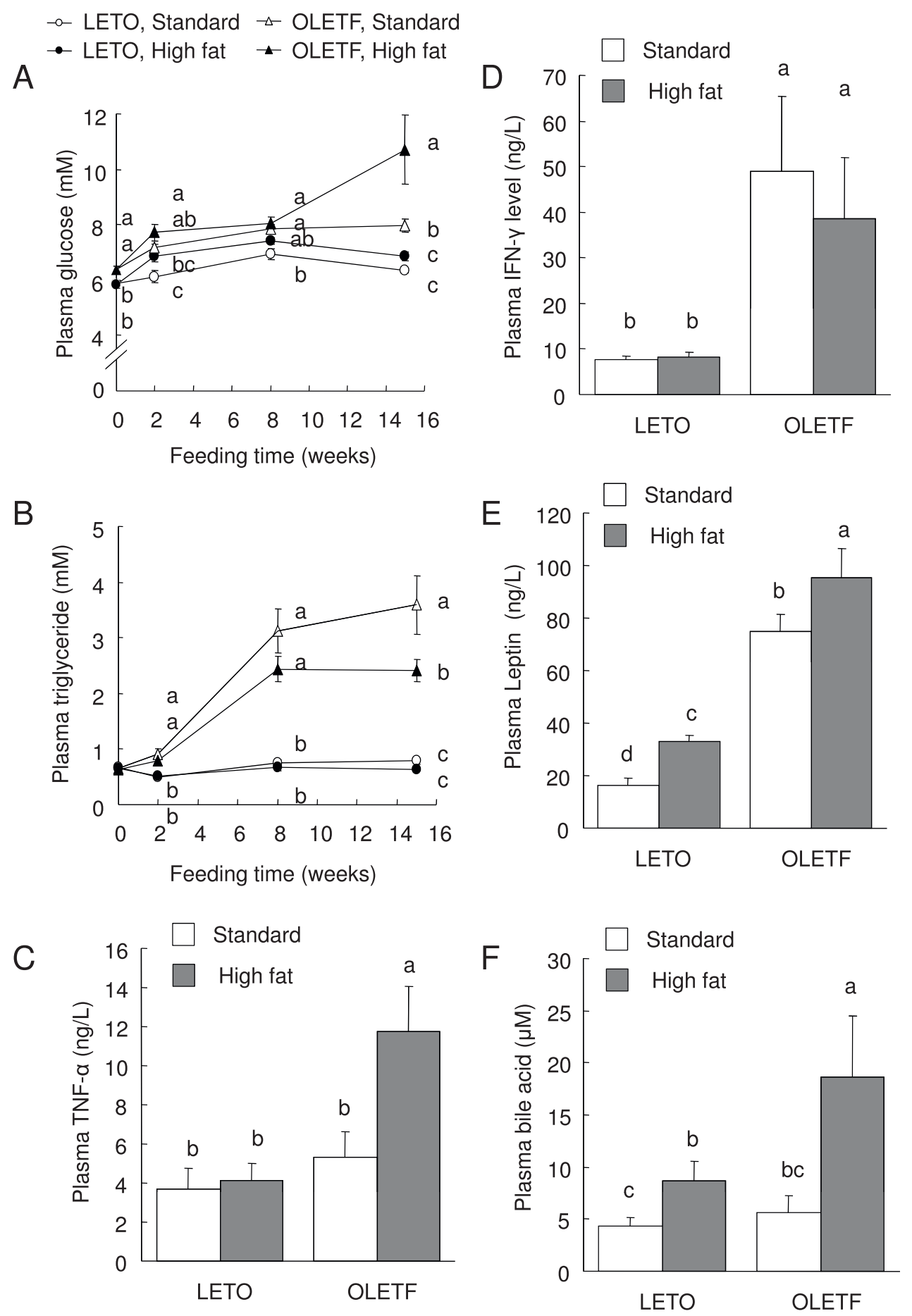

Figure 2 Plasma glucose (A), triglyceride (B), TNF- $\alpha$ (C), INF- $\gamma(\mathrm{D})$, leptin (E), and total bile acid (F) concentrations in the OLETF and LETO rats fed the standard and high fat diets. Glucose and triglyceride concentrations in the plasma collected from the tail vein at 2,8 , and 15 weeks after the start of feeding the experimental diets were measured. TNF- $\alpha$, INF- $\gamma$, leptin, and total bile acid concentrations in the plasma collected at the end of the experiment (at 16 weeks) were measured. Each value represents mean $\pm S E M, n=9$. Means without a common letter differ, $P<0.05$. $P$ values estimated by repeated measure 2 way ANOVA and 2-way ANOVA were $(A)<0.01$ for strain, $<0.01$ for diet, $<0.01$ for time, 0.24 for strain $x$ diet, $<0.01$ for strain $x$ time, $<0.02$ for diet $x$ time, and 0.07 for strain $x$ diet $x$ time, (B) $<0.01$ for strain, $<0.01$ for diet, $<0.01$ for time, 0.02 for strain $x$ diet, $<0.01$ for strain $x$ time, $<0.07$ for diet $x$ time, and 0.23 for strain $x$ diet $x$ time, (C) $<0.01$ for strain, $<0.03$ for diet, and 0.06 for strain $x$ diet, (D) $<0.01$ for strain, $<0.72$ for diet, and 0.86 for strain $x$ diet, (E) $<0.01$ for strain, 0.01 for diet, and 0.82 for strain $x$ diet, and (F) 0.10 for strain, $<0.01$ for diet, and 0.20 for strain $x$ diet. 
standard diet groups, and the OLETF rats showed lower Cr-EDTA excretion at 9 weeks as (by 2-way ANOVA). At 15 weeks, Cr-EDTA excretion in the OLETF rats fed the high fat diet was higher than that in any other group.

\section{TJ protein expression and cytoskeletal association in the} small intestine, cecum and colon

In the small intestine, claudin-1, claudin-3, and JAM-1 expression was influenced by $\operatorname{diet}(P<0.05,2$-way ANOVA, Fig. 4), with high-fat feeding resulting in a decrease in expression. Claudin-3 and JAM-1 expression levels were also influenced by strain, and were higher in the OLETF rats than in the LETO rats $(P<0.05,2$-way ANOVA).

The amounts of occludin, claudin-1, claudin-3, and JAM-1 in the detergent insoluble fractions, which correspond to the amounts associated with the actin cytoskeleton, in the small intestinal mucosa were influenced by diet in a manner very similar to that of their total expression $(P<0.05,2$-way ANOVA, Fig. 5$)$. The amounts of TJ proteins associated with actin cytoskeleton were decreased by feeding the high fat diets in both the OLETF and LETO rats, and were all higher in the OLETF rats than in the LETO rats, except for claudin-1 $(P<0.05,2$-way ANOVA).

There were no significant inter-group differences in the TJ protein expression levels or in the amounts present in the detergent insoluble fractions in the cecal and colonic mucosa (Fig. 6). No occludin was detected in the cecum when protein levels were assayed.

Immunofluorescence microscopy showed that claudin-3 was strongly expressed in the surface epithelial cells of the small intestine, especially in the villi, but not in the crypts (Fig. 7). A higher fluorescence intensity was observed for claudin-3 in the standard diet groups than in the high fat diet groups in each strain. The fluorescence intensity in the OLETF rats fed the standard diet was higher than that in the LETO rats fed the same diet. There were no significant differences in the pattern of the actin cytoskeleton stained by rhodamine-conjugated phalloidine among the groups. In the cecum and colon, claudin- 3 was expressed more in the villi than in the crypts in the surface epithelial cells however, no significant differences in fluorescence intensity were observed among the groups (data not shown).

\section{TJ integrity in Caco-2 cells exposed to rat bile juice and fat emulsion}

The total bile acid concentration in the rat bile juice collected was $15.0 \mathrm{mM}$. Consequently, the media with 1 , $2.5,5.0,10$, and $20 \%$ bile juice contained $0.188,0.375$, $0.75,1.5$, and $3.0 \mathrm{mM}$ total bile acids, respectively. 


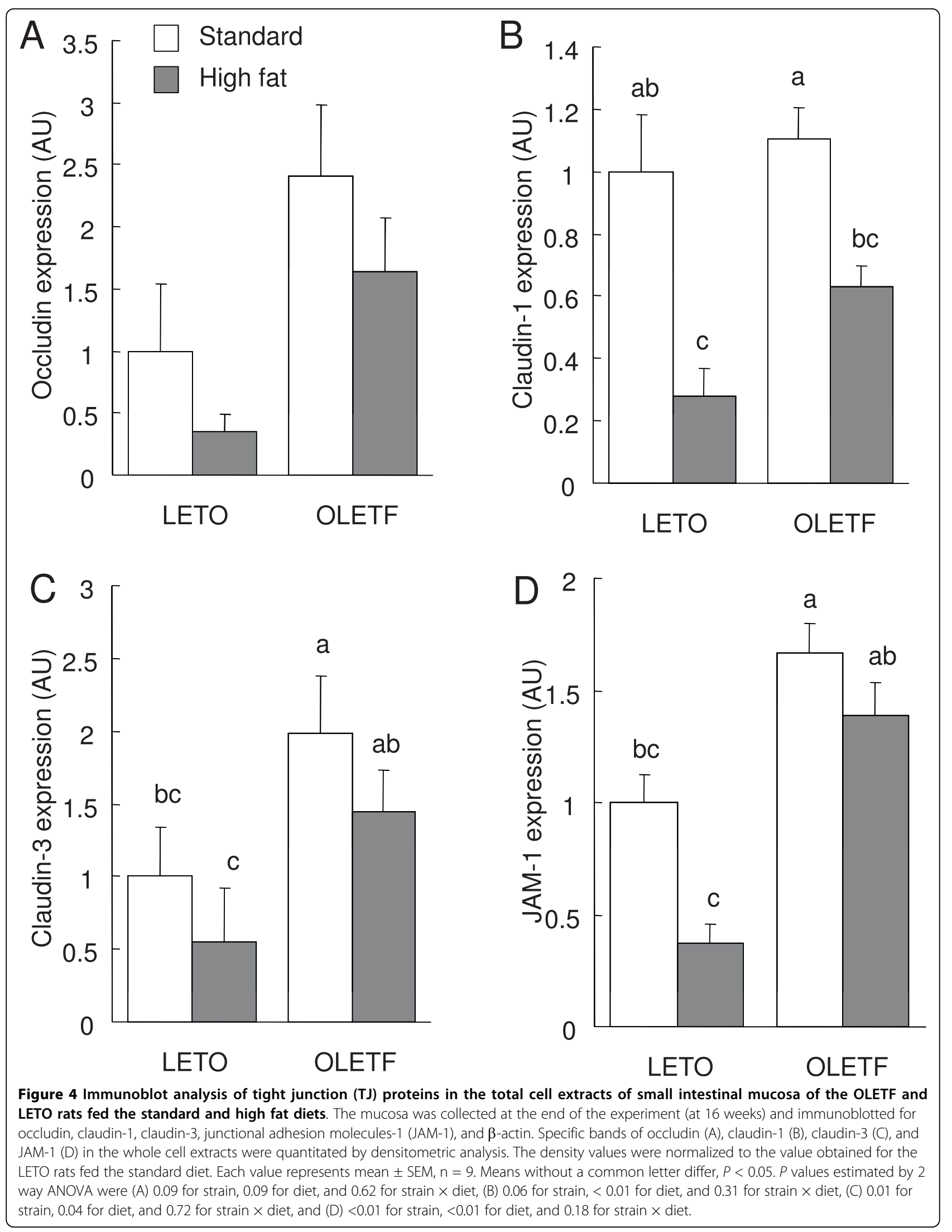




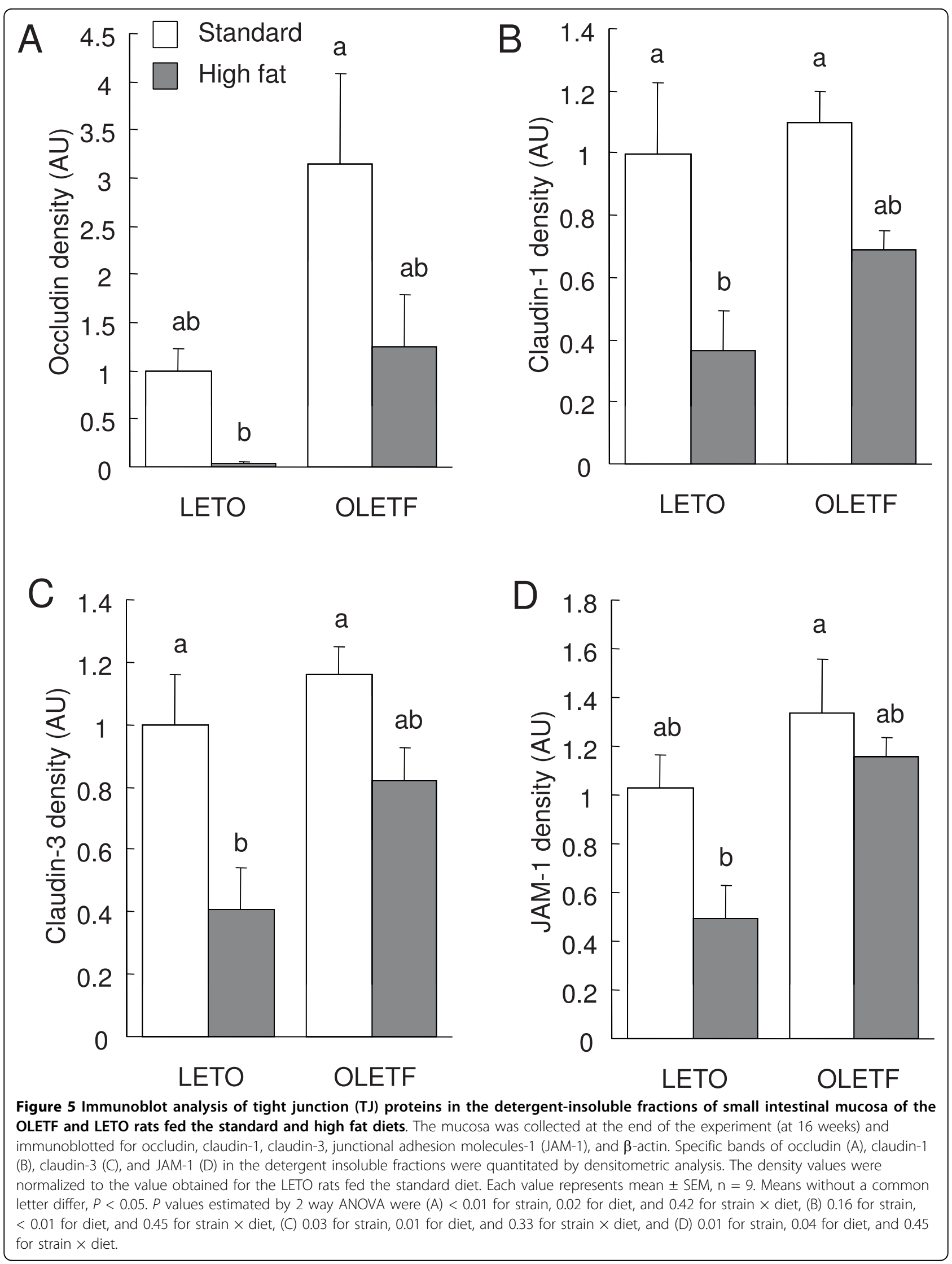




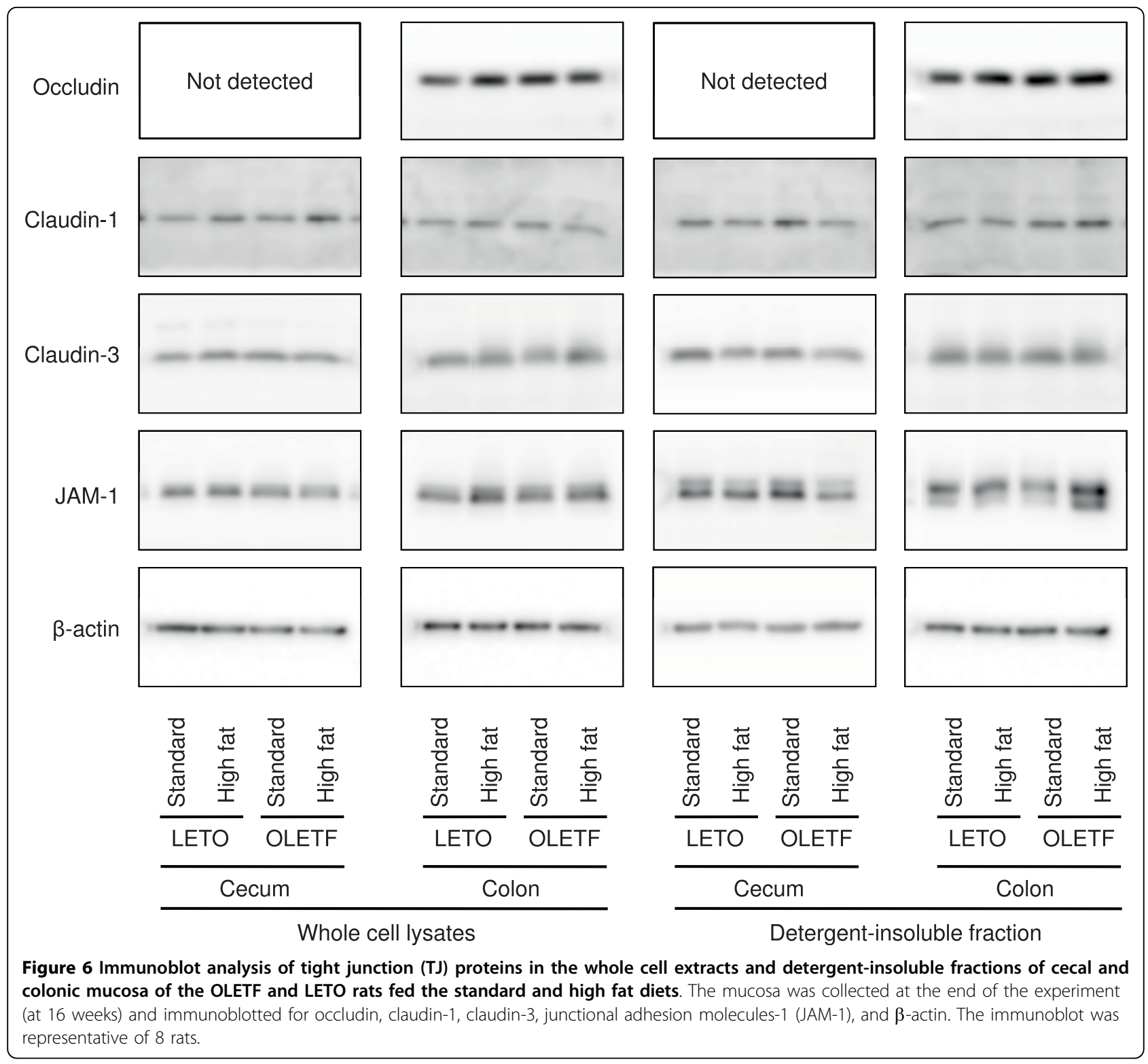

The exposure of the Caco-2 cell monolayers to 10 and $20 \%$, but not less than $10 \%$, rat bile juice periodically decreased the TER and increased lucifer yellow (LY) flux across the monolayers in a dose-dependent manner with significant differences compared with the control cells (Fig. 8A and 8B). The TER values for 10 and $20 \%$ bile juice at $72 \mathrm{~h}$ were approximately 50 and $17 \%$ of the initial values, respectively. The TER in the control cells was maintained at between 95 and $105 \%$ of the initial value. The LY fluxes for 10 and $20 \%$ bile juice were higher than that in the control cells and were approximately 7 - and 10 -fold higher than the control value, respectively. There were no significant differences in TER value at any time point or in LY flux among the control cells and the cells exposed to the bile juice at less than $10 \%$.
The TER values in the cells incubated with or without fat emulsion $(0.1,0.25,0.5$, and $1.0 \%)$ were sustained around the initial values until $48 \mathrm{~h}$ after the start of incubation, and no significant differences were found among treatments (Fig. 8C). The TER value for $1.0 \%$ fat emulsion at $72 \mathrm{hr}$ was approximately $60 \%$ of the initial value. The LY fluxes for 0.5 and $1.0 \%$ fat emulsion were 3- and 5-fold higher than the control values (Fig. 8D). There were no differences in TER value at any time point or in LY flux among the control cells and the cells exposed to the fat emulsion at less than $0.5 \%$.

The combination of bile juice (10\%) and fat emulsion (0.5\%) showed the additive effects on the LY flux, but not TER (Fig. 8E and 8F). The LY flux across the cells 


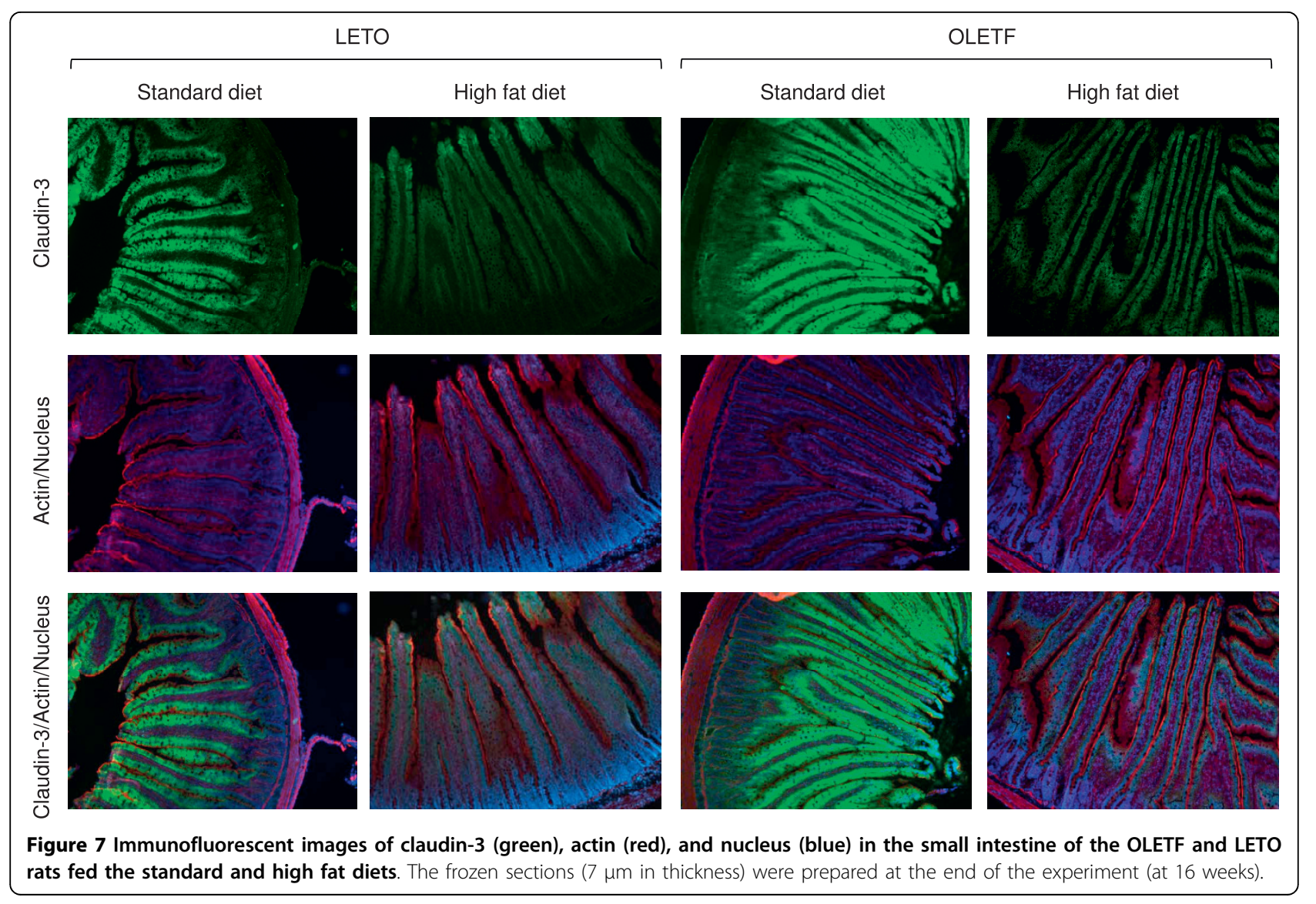

incubated with the combination of the bile juice and fat emulsion was higher than those with each.

\section{Expression of TJ proteins in Caco-2 cells exposed to rat bile juice and fat emulsion}

Bile juice treatment decreased the expression of TJ proteins, except for occludin, in a dose-dependent manner (Fig. 9A). Occludin expression in the cells incubated with 10 and $20 \%$ bile juice were lower and higher than the control value, respectively, whereas the expression of JAM- 1 and claudin-1 in cells incubated with 10 and 20\% bile juice and claudin-3 in those incubated with $20 \%$ bile juice were all lower than the control value.

Occludin expression in the cells treated with $1 \%$ fat emulsion was higher than in those treated with 0 and $0.5 \%$ (Fig. 9B) whereas the expression of JAM-1, claudin-1, and claudin-3 were lower in a dose-dependent manner. The expression of JAM- 1 and claudin- 1 in cells treated with 0.5 and $1 \%$ fat emulsion and claudin- 3 in those treated with $1 \%$ fat emulsion were all lower than the control value.

\section{Discussion}

Recently, it was reported that mice with genetic and high fat-induced obesity and diabetes displayed increased intestinal permeability [3-5]. The endotoxemia resulting from this permeability are thought to result in the development of inflammation and metabolic disorders $[3,4]$. However, the relationships between the occurrence of metabolic disorders and intestinal permeability, and the mediator(s) of the increase in permeability in cases of obesity remain unclear. The present study demonstrated that obesity by itself did not increase intestinal permeability in OLETF rats, a genetic obesity and type 2 diabetes model, whereas the feeding of a high fat diet increased intestinal permeability in both OLETF and their lean counter strain, LETO, rats. The increases in intestinal permeability were associated with reductions in $\mathrm{TJ}$ protein expressions in the small intestine, but not the large intestines (cecum and colon). In addition, the treatment of intestinal Caco-2 cells with a fat emulsion and rat bile juice remarkably increased epithelial permeability concomitantly with reductions in the expression of some $\mathrm{TJ}$ proteins.

Feeding the high fat diet increased the urinary excretion of PSP and Cr-EDTA, indicators of intestinal permeability, in both LETO and OLETF rats at 3, 9, and 15 weeks after the onset of feeding. Meanwhile, the intestinal permeability in the OLETF rats fed the standard diet was lower than or comparable with that in the 

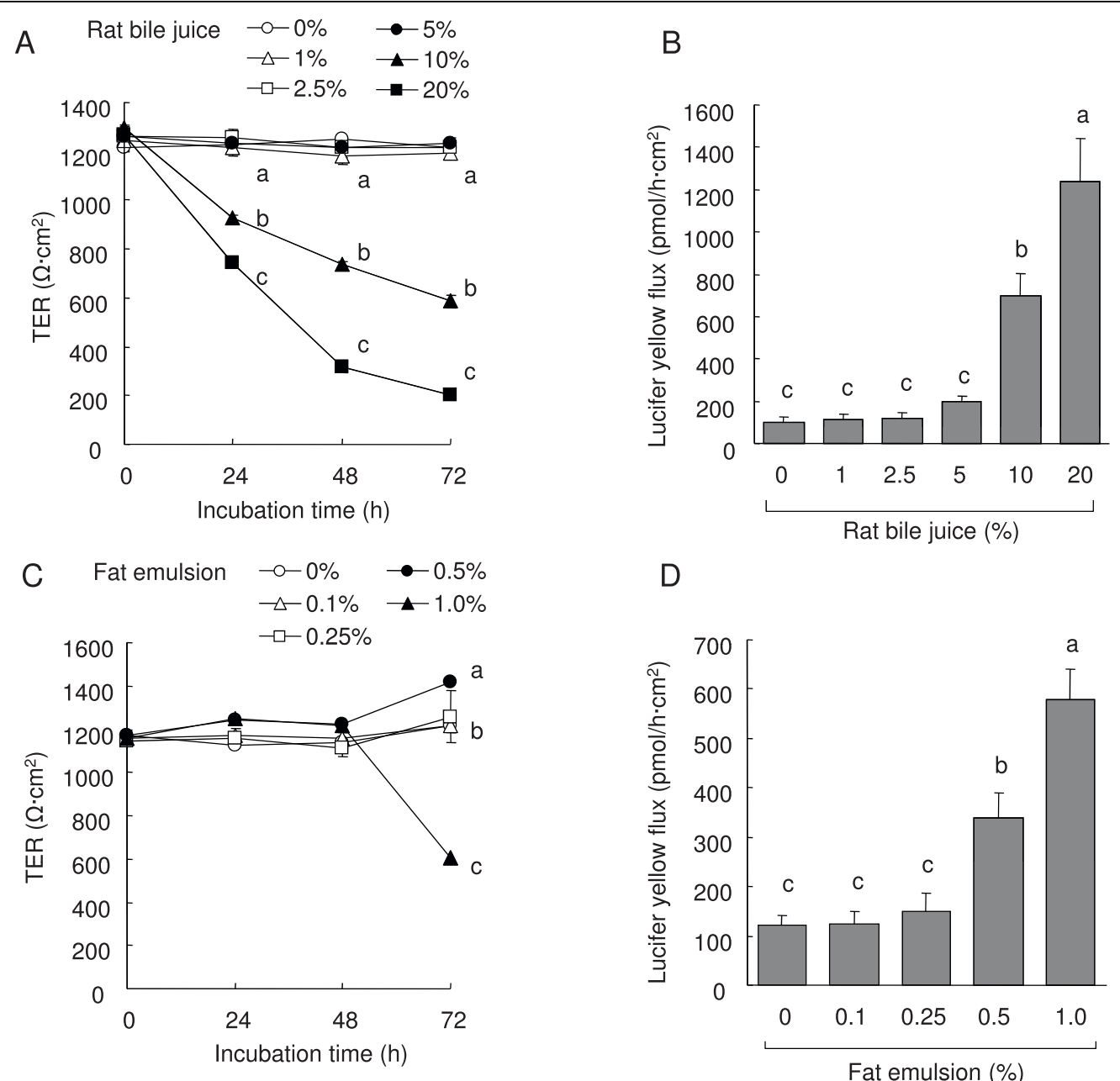

$\mathrm{D}$
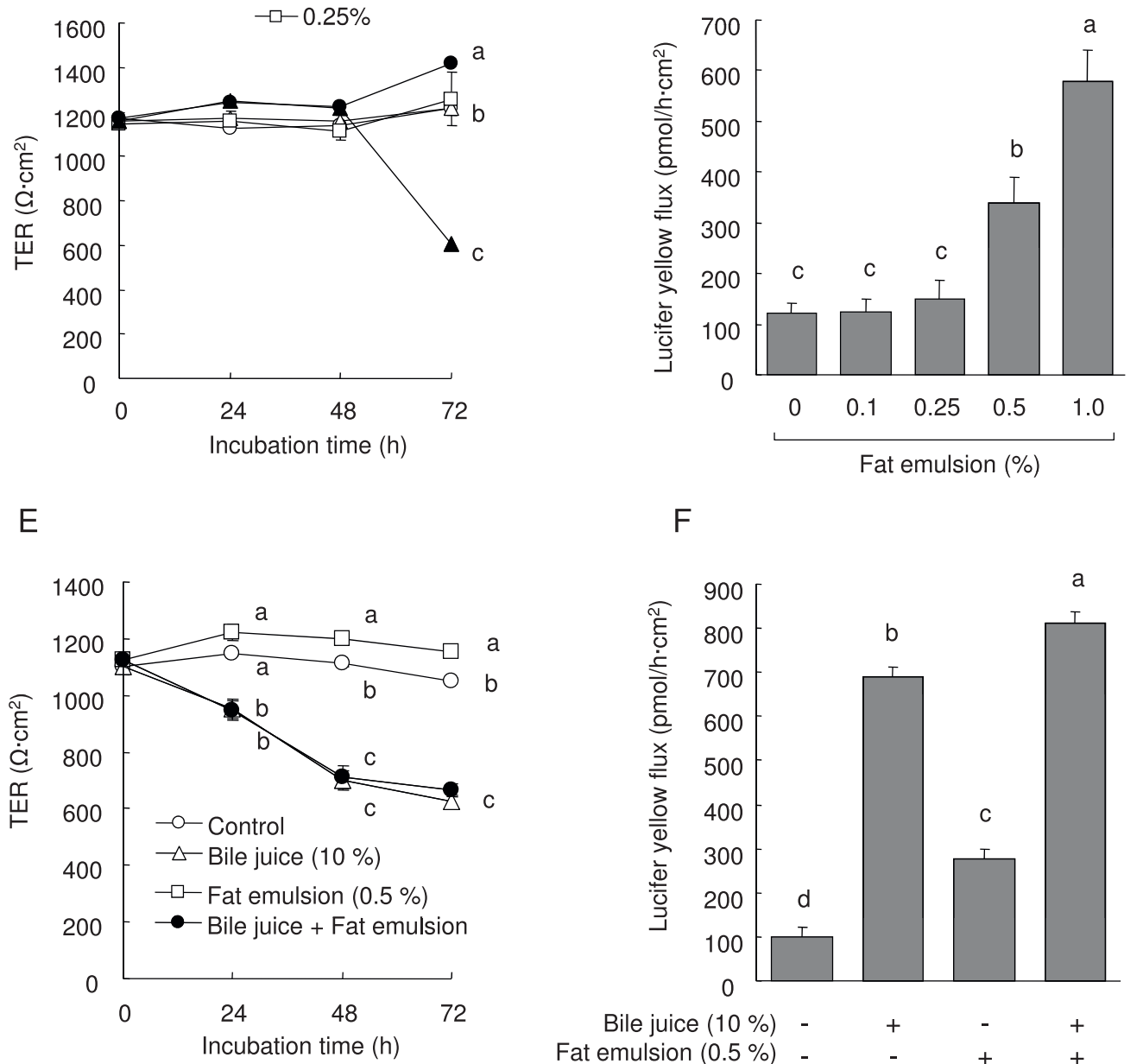

Figure 8 Transepithelial electrical resistance (TER) and lucifer yellow (LY) flux across the Caco-2 cell monolayers incubated with or without rat bile juice (2.5-20\%, $A$ and $B$ ) and fat emulsion (0.1-1.0\%, C and D) for $72 \mathrm{~h}$. TER (A and C) was measured at $0,24,48$, and $72 \mathrm{~h}$ after the start of incubation. LY flux (B and D) was measured for $3 \mathrm{~h}$ to $48 \mathrm{~h}$. Each value represents mean $\pm S E M, n=6$. Means without a common letter differ, $\mathrm{P}<0.05$. $P$ values estimated by repeated measure 1 way ANOVA or 1 way ANOVA were $(\mathrm{A})<0.01$ for time, $<$ 0.01 for treatment, and $<0.01$ for time $\times$ treatment, (B) $<0.01$, (C) $0<0.01$ for time, $<0.01$ for treatment, and $<0.01$ for time $\times$ treatment, and (D) $<0.01$. 
a
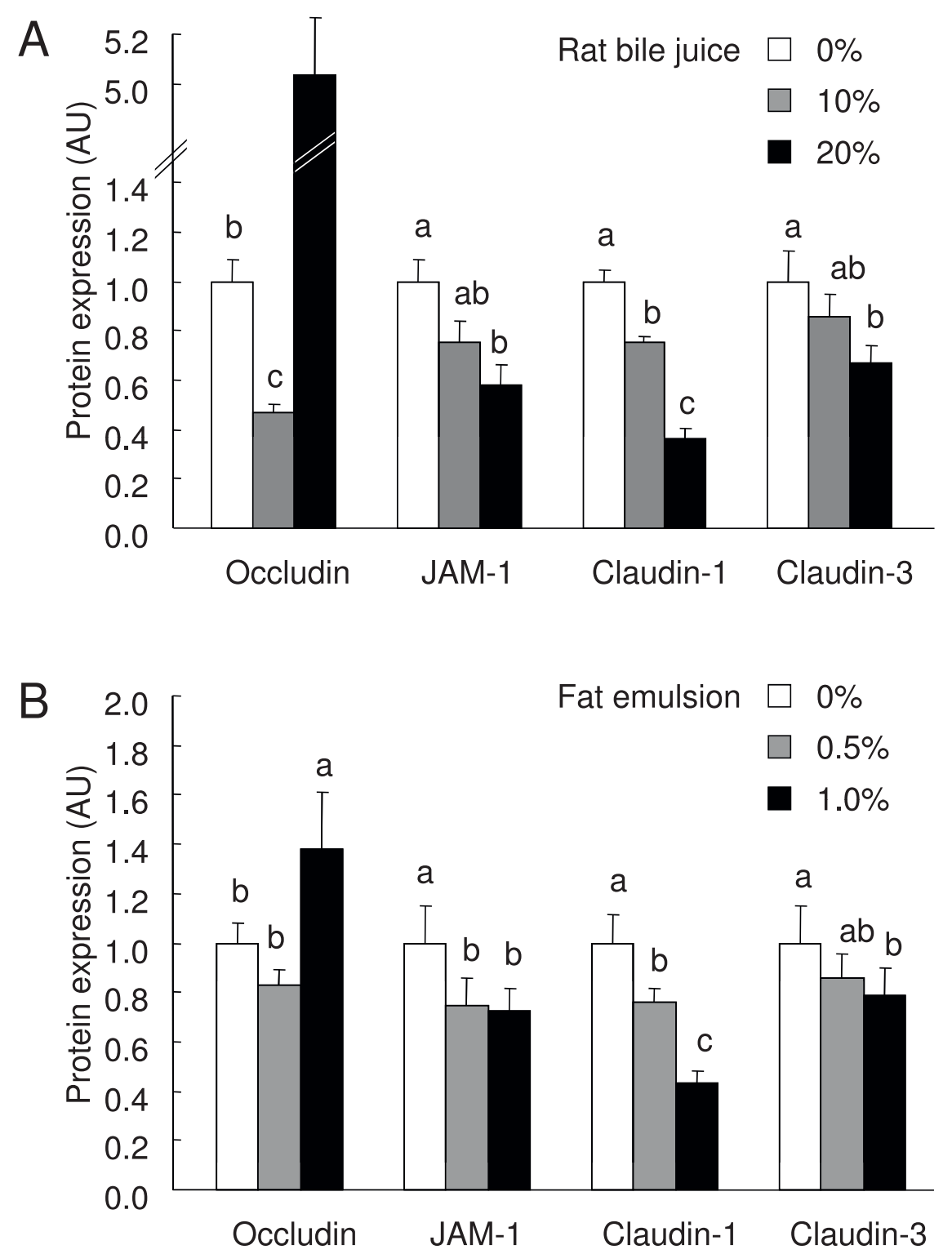

Figure 9 Immunoblot analysis of tight junction (TJ) proteins in the whole cell extracts of the Caco- 2 cell monolayers incubated with or without rat bile juice (10 and $20 \%, A$ and $B$ ) and fat emulsion $(0.5$ and $1.0 \%, A$ and C) for $\mathbf{7 2} \mathbf{~ h}$. The whole cell extracts were prepared $72 \mathrm{~h}$ after the start of incubation and immunoblotted for occludin, claudin-1, claudin-3, junctional adhesion molecules-1 (JAM-1), and $\beta$-actin. Specific bands of occludin, claudin-1, claudin-3, and JAM-1 were quantitated by densitometric analysis. The density values were normalized to the value obtained for the control monolayers. Each value represents mean $\pm S E M, n=6$. Means without a common letter differ, $P<0.05$. $P$ values estimated by 1 way ANOVA were $<0.01$ in each TJ protein expression in the cells treated with the rat bile juice (A) and fat emulsion (B).

LETO rats fed the same diet in all permeability tests. The OLETF rats fed the standard diet presented with metabolic disorders such as obesity and glucose intolerance, and the severity of these disorders increased with age although feeding with the high fat diet exacerbated them. These results suggest that these metabolic disorders themselves do not trigger the increase in intestinal permeability in the OLETF rats, instead, the high-fat feeding is the cause of the increase in intestinal permeability. The high fat-induced increase in intestinal permeability in the OLETF rats was greater at 15 weeks than at 3 or 9 weeks, indicating that prolonged feeding of the high fat diet aggravated the increase in intestinal permeability in the OLETF rats, but not in the LETO rats. The differences found between the 2 strains suggest that factors other than dietary fat affected intestinal 
permeability in the OLETF rats at 15 weeks. Only the OLETF rats fed the high fat diet showed higher both TNF- $\alpha$ and IFN- $\gamma$ levels in the plasma. It is reported that TNF- $\alpha$ and IFN- $\gamma$ synergize to impair intestinal barrier function in the intestinal cells [18]. The simultaneous increase in the TNF- $\alpha$ and IFN- $\gamma$ is a candidate for the greater permeability in the OLETF rats fed the high fat diet for15 weeks.

To explore the mechanisms underlying the high fatinduced increase in intestinal permeability, we evaluated the expression of $\mathrm{TJ}$ proteins, occludin, claudin-1, claudin-3, and JAM-1, and their association with the actin cytoskeleton in the small intestine, cecum and colon of rats. Feeding the high fat diet clearly decreased the expression of some $\mathrm{TJ}$ proteins and their cytoskeletal association in the small intestines of LETO and OLETF rats, although we did not find any statistical differences in occludin expression ( $P=0.09,2$-way ANOVA) in the small intestine. The decrease in the cytoskeletal association of TJ proteins was considered to originate in the decrease in their expression due to the similarities observed. In addition, the high fat-induced reduction in claudin-3 expression in the small intestine of the LETO and OLETF rats was confirmed by immunofluorescence microscopy. These results agree with those of a previous report showing that high-fat feeding increased intestinal permeability and decreased the expression of $\mathrm{TJ}$ proteins in the mouse jejunum [4]. Interestingly, we did not find any high fat-induced decreases in TJ protein expression or cytoskeletal association in the cecum and colon of the LETO and OLETF rats. These results indicate that the decreases in TJ protein expression and cytoskeletal association in the small intestine are responsible for the high fat diet-induced increase in intestinal permeability in the LETO and OLETF rats. Diffusion of bacterial endotoxins into the blood stream as a result of the increase in intestinal permeability is thought to be associated with the systemic inflammation and development of metabolic disorders in obesity and diabetes $[3,4,19]$. Our results suggest that small intestinal bacteria contributes to the endotoxemia in the high fat-induced obesity models although we did not assess the plasma endotoxin levels and more bacteria are known to colonize the large intestines than the small intestine.

We suggest excessive dietary fat itself and increased levels of bile juice in the lumen as possible mediators of the increase in permeability in the small intestine of rats fed the high fat diet. The reasons for our suggestion are 1) the high-fat feeding increased the luminal fat concentration in both the LETO and OLETF rats, 2) the increases in plasma bile acids levels by the high-fat feeding in both the LETO and OLETF rats possibly result from their secretion into the lumen in these rats 3 ) the LETO rats fed the high fat diet exhibited higher intestinal permeability without any change in plasma TNF- $\alpha$ and IFN- $\gamma$, and 4) TJ protein expression and cytoskeletal association were not affected by the high-fat feeding in the large intestine as most of that dietary fat did not reach to the large intestine and the concentration(s) of bile juice or its components was much lower in the large intestine than in the small intestine [20]. As expected, the exposure of Caco- 2 cells to the fat emulsion (0.5 and $1 \%)$ and rat bile juice (10 and $20 \%$ ) markedly increased TJ permeability with concomitant reductions in the expression of some $\mathrm{TJ}$ proteins, indicating that the excessive dietary fat and bile juice negatively modulate intestinal TJ integrity. Remarkably, these results in the Caco- 2 cells partially mimicked the high fat diet-induced reduction in $\mathrm{TJ}$ proteins in the small intestines of rats, except for occludin, whereas the bile juice at $\sim 5 \%$ or fat emulsion at $\sim 0.5 \%$ did not have any effects on TJ permeability in the Caco- 2 cells. The effective dose of the bile juice was $10 \%$ or more, and the medium with $10 \%$ bile juice contained $1.5 \mathrm{mM}$ bile acids as the total bile acid concentration in the bile juice was $15.0 \mathrm{mM}$. The luminal concentrations of the total bile acids are reported to be $\sim 3 \mathrm{mM}$ in the small intestine, $\sim 1 \mathrm{mM}$ in the cecum, and $\sim 0.5 \mathrm{mM}$ in the colon of rats [20]. The reason why the feeding of a high fat diet did not impair $\mathrm{TJ}$ protein expression in the large intestines seems to be that the concentrations of bile juice and dietary fat were below the concentrations needed to be effective. The plasma bile acids were unlikely to influence the intestinal $\mathrm{TJ}$ permeability, because the plasma levels were much lower than luminal levels. Furthermore, the additive effect on the LY flux observed by the combination of bile juice and fat emulsion indicates that their individual effects do not interact each other although they exist together in the intestinal lumen. These results observed in the Caco-2 cells indicated that the high fat feeding-induced impairment of the TJ expressions in the small intestine of the LETO and OLETF rats was caused by the increases in the luminal fat amount and bile juice.

Some reports have examined the effects of the fatty acids and the bile acids on intestinal TJ integrity. Oleic acid, which is a major fatty acid composed of the fat emulsion used in our experiment, as well as $\gamma$-linoleic, and docosahexaenoic acids reportedly increased $\mathrm{TJ}$ permeability in Caco- 2 cells [21,22]. In these reports, the fatty acids were suggested to penetrate the plasma membrane of the cells and disturb TJ function. Meanwhile, Raimondi et al. [23] reported that unconjugated bile acids increased TJ permeability via occludin dephosphorylation, but not via any reduction in $\mathrm{TJ}$ protein expression, in Caco- 2 cells. The differences between the previous results and our observation may be attributed to other components in the bile juice such as bilirubin 
and cholesterol. In addition, bile acids are conjugated with glycine and taurine in bile juice, and these conjugations provide hydrophilicity for the bile acids, which possibly affects their biological effects. In addition, Araki et al. reported that cholic acid induced the TER decrease through the generation of reactive oxygen species in the Caco-2 cells [24]. The mechanism underlying the reduction in $\mathrm{TJ}$ protein expression induced by the fat emulsion and bile juice remain under investigation.

The LETO rats fed the high fat diet showed the increase in the intestinal permeability without any increases in the plasma inflammatory cytokines levels, TNF- $\alpha$ or IFN- $\gamma$ although the increased permeability resulting in the exdotoxemia is considered to be an important factor to develop the inflammatory tone in the obesity [3]. Meanwhile, the OLETF rats fed the standard diet showed the increase in the plasma IFN- $\gamma$ level without increasing the permeability. These results may indicate that the LETO rats fed the high fat diet needed longer time to show the systemic inflammation resulting from the increase in permeability and that not only the intestinal permeability but also the metabolic changes with the accumulation of body fat contribute to the development of inflammatory tone in the obesity.

As described above, the OLETF rats fed the standard diet did not exhibit any increase in intestinal permeability in comparison to the counter strain LETO rats fed the same diet, although 2 obese mouse models, the leptin-deficient $(\mathrm{ob} / \mathrm{ob})$ and leptin receptor-deficient $(\mathrm{db} /$ $\mathrm{db})$ strains, reportedly showed increases in intestinal permeability with a concomitant reduction in the expression of TJ proteins, ZO-1 and occludin [5]. These 3 animal models (OLETF rats, ob/ob mice, and $\mathrm{db} / \mathrm{db}$ mice) are resistant to the hypothalamic actions of hormones, and experience hyperphagia together with subsequent obesity and metabolic disorders. However, their molecular mechanisms are different. The OLETF rat is a spontaneous cholecystokinin-1 receptor knock out model possessing defects in the satiety action of cholecystokinin $[25,26]$. On the other hand, the ob/ob and $\mathrm{db} / \mathrm{db}$ mice present a defect in leptin activity: the ob/ob mice express a truncated inactive form of leptin, and the $\mathrm{db} / \mathrm{db}$ mice express a signaling-incompetent long isoform of the leptin receptor [27]. Some reports have demonstrated that leptin ameliorates ischemia-reperfusion-induced mucosal injuries in the small intestine of rats through the stimulation of cell proliferation and prevention of cell apoptosis [28]. Leptin may also have an important role in the expression and function of intestinal TJs similar to that of epidermal growth factor [29]. Our results showed that the OLETF rats had higher plasma leptin levels and higher $\mathrm{TJ}$ protein expression levels in the small intestine than did the LETO rats, both of which support this hypothesis.
However, further studies are required to clarify the possible role of leptin on TJ function.

\section{Conclusions}

The feeding of a high fat diet in rats increases intestinal $\mathrm{TJ}$ permeability resulting from the reduction in TJ protein expression in the small, but not in the large intestine. The possible mediators of the increase in permeability are excessive dietary fat itself and the increased levels of bile juice in the lumen. Meanwhile, the obesity and the metabolic disorders themselves were not the primary factors in the increase in intestinal permeability.

\section{Abbreviations}

ANOVA: Analysis of variance; AUC: Area under the glucose curve; HOMA-IR: Homeostasis model assessment insulin resistance; IFN- $\gamma$ : Interferon- $\gamma_{i}$ JAM: Junctional adhesion molecule; LETO: Long Evans Tokushima Otsuka; LY: lucifer yellow; OGTT: Oral glucose tolerance test; OLETF: Otsuka Long Evans Tokushima Fatty; PSP: Phenolsulfonphthalein; TER: Transepithelial electrical resistance; TJ: Tight junction; TNF- $\alpha$ : tumor necrosis factor- $\alpha$; ZO: zonula occludens.

\section{Acknowledgements}

This research was partially supported by Japan Society for the Promotion of Science, Grant-in-Aid for Young Scientists (B) 21780117 and Uehara Memorial Foundation.

\section{Author details}

${ }^{1}$ Division of Applied Bioscience, Research Faculty of Agriculture, Hokkaido University, Sapporo, Hokkaido, Japan. ${ }^{2}$ Graduate School of Biosphere Science, Hiroshima University, Higashi-Hiroshima, Hiroshima, Japan.

\section{Authors' contributions}

TS and HH designed the study. TS performed all experiments, assays, and statistical analysis. TS and $\mathrm{HH}$ analyzed the data. TS wrote the manuscript and $\mathrm{HH}$ helped to write the manuscript. All authors read and approved the final manuscript.

\section{Competing interests}

The authors declare that they have no competing interests.

Received: 3 December 2009 Accepted: 12 March 2010 Published: 12 March 2010

\section{References}

1. Kahn SE, Hull RL, Utzschneider KM: Mechanisms linking obesity to insulin resistance and type 2 diabetes. Nature 2006, 444:840-846.

2. Hotamisligil GS: Inflammation and metabolic disorders. Nature 2006, 444:860-867.

3. Cani PD, Amar J, Iglesias MA, Poggi M, Knauf C, Bastelica D, Neyrinck AM, Fava F, Tuohy KM, Chabo C, Waget A, Delmee E, Cousin B, Sulpice T, Chamontin B, Ferrieres J, Tanti JF, Gibson GR, Casteilla L, Delzenne NM, Alessi MC, Burcelin R: Metabolic endotoxemia initiates obesity and insulin resistance. Diabetes 2007, 56:1761-1772.

4. Cani PD, Bibiloni R, Knauf C, Waget A, Neyrinck AM, Delzenne NM, Burcelin R: Changes in gut microbiota control metabolic endotoxemiainduced inflammation in high-fat diet-induced obesity and diabetes in mice. Diabetes 2008, 57:1470-1481.

5. Brun P, Castagliuolo I, Di Leo V, Buda A, Pinzani M, Palu G, Martines D: Increased intestinal permeability in obese mice: new evidence in the pathogenesis of nonalcoholic steatohepatitis. Am J Physiol Gastrointest Liver Physiol 2007, 292:G518-525.

6. Gonzalez-Mariscal L, Betanzos A, Nava P, Jaramillo BE: Tight junction proteins. Prog Biophys Mol Biol 2003, 81:1-44. 
7. Furuse $M$, Hirase $T$, Itoh M, Nagafuchi A, Yonemura S, Tsukita S: Occludin: a novel integral membrane protein localizing at tight junctions. J Cell Biol 1993, 123:1777-1788

8. Furuse M, Fujita K, Hiiragi T, Fujimoto K, Tsukita S: Claudin-1 and -2: novel integral membrane proteins localizing at tight junctions with no sequence similarity to occludin. J Cell Biol 1998, 141:1539-1550.

9. Martin-Padura I, Lostaglio S, Schneemann M, Williams L, Romano M Fruscella P, Panzeri C, Stoppacciaro A, Ruco L, Villa A, Simmons D, Dejana E: Junctional adhesion molecule, a novel member of the immunoglobulin superfamily that distributes at intercellular junctions and modulates monocyte transmigration. J Cell Biol 1998, 142:117-127.

10. Madara $\mathrm{JL}$ : Intestinal absorptive cell tight junctions are linked to cytoskeleton. Am J Physiol 1987, 253:C171-175.

11. Suzuki T, Hara H: Quercetin enhances intestinal barrier function through the assembly of zonula [corrected] occludens-2, occludin, and claudin- 1 and the expression of claudin-4 in Caco-2 cells. J Nutr 2009, 139:965-974.

12. Suzuki $\mathrm{T}$, Hara $\mathrm{H}$ : Ingestion of guar gum hydrolysate, a soluble and fermentable nondigestible saccharide, improves glucose intolerance and prevents hypertriglyceridemia in rats fed fructose. J Nutr 2004, 134:1942-1947.

13. Nakamura J, Takada S, Ohtsuka N, Heya T, Yamamoto A, Kimura T, Sezaki H: An assessment of indomethacin-induced gastrointestinal mucosal damage in-vivo: enhancement of urinary recovery after oral administration of phenolsulfonphthalein in rats. J Pharm Pharmacol 1983, 35:369-372.

14. Ten Bruggencate SJ, Bovee-Oudenhoven IM, Lettink-Wissink ML, Meer Van der R: Dietary fructooligosaccharides increase intestinal permeability in rats. J Nutr 2005, 135:837-842.

15. Downes AM, McDonald IW: THE CHROMIUM-51 COMPLEX OF ETHYLENEDIAMINE TETRAACETIC ACID AS A SOLUBLE RUMEN MARKER. Br J Nutr 1964, 18:153-162.

16. Basuroy S, Seth A, Elias B, Naren AP, Rao R: MAPK interacts with occludin and mediates EGF-induced prevention of tight junction disruption by hydrogen peroxide. Biochem J 2006, 393:69-77.

17. Laemmli UK: Cleavage of structural proteins during the assembly of the head of bacteriophage T4. Nature 1970, 227:680-685.

18. Wang F, Graham W, Wang Y, Witkowski ED, Schwarz BT, Turner JR: Interferon-gamma and tumor necrosis factor-alpha synergize to induce intestinal epithelial barrier dysfunction by up-regulating myosin light chain kinase expression. Am J Pathol 2005, 166:409-419.

19. Tsukumo DM, Carvalho-Filho MA, Carvalheira JB, Prada PO, Hirabara SM, Schenka AA, Araujo EP, Vassallo J, Curi R, Velloso LA, Saad MJ: Loss-offunction mutation in Toll-like receptor 4 prevents diet-induced obesity and insulin resistance. Diabetes 2007, 56:1986-1998.

20. Hagio M, Matsumoto M, Fukushima M, Hara H, Ishizuka S: Improved analysis of bile acids in tissues and intestinal contents of rats using LC/ ESI-MS. J Lipid Res 2009, 50:173-180.

21. Usami M, Komurasaki T, Hanada A, Kinoshita K, Ohata A: Effect of gammalinolenic acid or docosahexaenoic acid on tight junction permeability in intestinal monolayer cells and their mechanism by protein kinase $C$ activation and/or eicosanoid formation. Nutrition 2003, 19:150-156

22. Aspenstrom-Fagerlund B, Sundstrom B, Tallkvist J, Ilback NG, Glynn AW: Fatty acids increase paracellular absorption of aluminium across Caco-2 cell monolayers. Chem Biol Interact 2009, 181:272-278.

23. Raimondi F, Santoro P, Barone MV, Pappacoda S, Barretta ML, Nanayakkara M, Apicella C, Capasso L, Paludetto R: Bile acids modulate tight junction structure and barrier function of Caco-2 monolayers via EGFR activation. Am J Physiol Gastrointest Liver Physiol 2008, 294:G906-913.

24. Araki Y, Katoh T, Ogawa A, Bamba S, Andoh A, Koyama S, Fujiyama Y, Bamba T: Bile acid modulates transepithelial permeability via the generation of reactive oxygen species in the Caco-2 cell line. Free Radic Biol Med 2005, 39:769-780.

25. Miyasaka K, Kanai S, Ohta M, Kawanami T, Kono A, Funakoshi A: Lack of satiety effect of cholecystokinin (CCK) in a new rat model not expressing the CCK-A receptor gene. Neurosci Lett 1994, 180:143-146.

26. Covasa M, Ritter RC: Attenuated satiation response to intestinal nutrients in rats that do not express CCK-A receptors. Peptides 2001, 22:1339-1348.

27. Chen $\mathrm{H}$, Charlat $\mathrm{O}$, Tartaglia LA, Woolf EA, Weng X, Ellis SJ, Lakey ND, Culpepper J, Moore KJ, Breitbart RE, Duyk GM, Tepper RI, Morgenstern JP: Evidence that the diabetes gene encodes the leptin receptor: identification of a mutation in the leptin receptor gene in $\mathrm{db} / \mathrm{db}$ mice. Cell 1996, 84:491-495.

28. Hacioglu A, Algin C, Pasaoglu O, Pasaoglu E, Kanbak G: Protective effect of leptin against ischemia-reperfusion injury in the rat small intestine. BMC Gastroenterol 2005, 5:37.

29. Suzuki T, Seth A, Rao R: Role of phospholipase Cgamma-induced activation of protein kinase Cepsilon (PKCepsilon) and PKCbetal in epidermal growth factor-mediated protection of tight junctions from acetaldehyde in Caco-2 cell monolayers. J Biol Chem 2008, 283:3574-3583.

doi:10.1186/1743-7075-7-19

Cite this article as: Suzuki and Hara: Dietary fat and bile juice, but not obesity, are responsible for the increase in small intestinal permeability induced through the suppression of tight junction protein expression in LETO and OLETF rats. Nutrition \& Metabolism 2010 7:19.

\section{Submit your next manuscript to BioMed Central and take full advantage of:}

- Convenient online submission

- Thorough peer review

- No space constraints or color figure charges

- Immediate publication on acceptance

- Inclusion in PubMed, CAS, Scopus and Google Scholar

- Research which is freely available for redistribution
C Biomed Central 